\title{
लाहौल-स्पिति की लोकगाथाओं में संगीत
}

\section{सार संक्षेपिका}

हिमाचल प्रदेश के जनजातीय क्षेत्र लाहौल-स्पिति एक प्राचीन सांस्कृतिक एंव ऐतिहासिक जनपद होने के कारण लोक साहित्य एवं लोक संगीत में समृद्ध है। एक ही जनपद के अन्तर्गत होने पर भी यहां की लोक संस्कृति तथा लोकगीतों में विभिन्नता पाई जाती है। कला एवं संस्कृति से सम्पन्न इस क्षेत्र की पृष्ठभूमि में गूंजती हुई लोकगाथाओं ने सदैव लोगों को प्रभावित किया है। लोकगाथाओं की स्वर रचना कहीं न कहीं राग छाया से आच्छदित रहती है। इनमें अनेक रागों के स्पष्ट एवं सुक्ष्म कणों को गहराई से जानने तथा लोकगाथाओं में रूची रखने वाले सभी श्रोताओं को जनजातीय क्षेत्र की इस लुप्त होती सांगीतिक विधा से अवगत कराने का प्रयास किया गया है। लाहौल-स्पिति में सबसे समृद्ध परम्परा लोकगाथाओं पर आधारित गीतों की रही है। लाहौल क्षेत्र में इन गीतों को 'घुरे' कहा जाता है। इन लोकगाथाओं में अधिकतर सामाजिक, ऐतिहासिक व धार्मिक घटनाओं का वर्णन रहता है। जिनमें स्पिति में गाए जाने वाले 'नामथर' में केवल पौराणिक व धार्मिक गाथाएं ही होती है। जबकि 'ज्ञालशू' में सामाजिक ऐतिहासिक व धार्मिक तीनों प्रकार की गाथाओं का वर्णन का होता है। इन दोनों क्षेत्रों की लोकगाथाओं में केवल भाषा का अन्तर है। लाहौली लोकगाथाओं में जहां मिश्रित बोलियों का प्रयोग होता है वहीं स्पिति में लोकगाथाएं केवल भोटी भाषा में ही गाई जाती है। इन गाथाओं में जीवन के प्रत्येक पहलुओं का वर्णन मिलता है। यहां की अधिकतर लोकगाथाएं ताल रहित तथा अनिबद्ध प्रकार के है। इनमें केवल हाथ से थाप दी जाती है जिससे अप्रत्यक्ष रूप से लय अथवा ताल का आभास होता है जो दादरा, चाचर तथा दीपचन्दी ताल के समान प्रतीत होते है। इन गीतों में पद के आरम्भ और अन्त में ' $\mathrm{S}$ ' और 'ओ' का स्वर उच्चारण हमेशा सुनने को मिलता है।

बीज शब्द

लाहौल-स्पिति, लोकगाथा

लोकगाथा

भारतीय लोक साहित्य में लोकगाथाओं का महत्वपूर्ण स्थान है, जिनकी परम्परा अति प्राचीन है। जब से मानव ने अपने भावों को परस्पर व्यक्त करने के लिए वाणी का प्रयोग आरम्भ किया होगा, तभी से भाषा ने भी अपना स्वरूप बनाया होगा और लोकगाथाओं का जन्म भी हम तभी मान सकते हैं। लोकगाथाओं की परिधि संसार की सीमा से साथ-साथ आदिकाल से लेकर आज तक बढ़ती जा रही है। संस्कृति एवं मानव सभ्यता की ज्ञान की गारिमा तथा आध्यात्मवाद की अभिव्यंजना लोकगाथाओं के माध्यम से सहज और सम्भव है। आज भी ग्राम्य जीवन में विशेष अवसर पर लोकगाथाओं को महत्वपूर्ण स्थान दिया जाता है। लोकगाथाएं जन समुदाय के लिए हर्ष-विवाद, सुख-दुःख, प्रेम-प्रसंग, विरह-वेदना और जीवन की यथार्थ पूर्ण घटनाएं आदि लोकगाथाओं में सहज प्रतीकों के माध्यम से मुखारित हुआ करती है। लोकगाथा कथात्मक गीत होने के कारण लोक साहित्य का अभिन्न अंग है। यह किसी व्यक्ति विशेष, प्राकृतिक घटनाओं और सामाजिक घटनाओं से सम्बन्धित होती है। गेयात्मक होने के कारण इन्हें विशेष अवसर पर ही गाया जाता है। वस्तुतः लोकगाथाओं में सम्पूर्ण जीवन की अभिव्यक्ति होती है। इसलिए अधिक लम्बी होने के 
कारण लोक गीतों की भांति जनसमुदाय की कंठमाला बनकर कुछ जातियों या व्यक्तियों के दायरे में सीमित रहकर अनेक लोकगाथाएं जीवनोपार्जन का साधन भी बन गई है। लोकगीतों की भांति लोकगाथाओं में भी समय-समय पर लोकरचनाकारों द्वारा परिवर्तन तथा संर्वधन किया जाता है। उसके मृत रूप में कुछ अंश छूटते जाते है और कुछ जुड़ते चले जाते हैं। जिस प्रकार कोई नदी अपने स्र्रोत से अत्यन्त पतली धारा के रूप में निकलती है; और बाद में अनेक छोटी-छोटी नदियां नाले उसमें मिलते जाते हैं और अन्त में उनका रूप इतना विस्तृत हो जाता है कि पहचानना कठिन हो जाता है, उसी प्रकार लोकगाथाओं के मूल रूप में भी लोकरचनाकारों द्वारा इतना परिवर्तत किया जाता है कि उसके मौलिक रूप का पता ही नहीं चलता। इस प्रकार जनजातीय क्षेत्र की यह लोकगाथाएं एक पीढ़ी से दूसरी पीढ़ी, एक स्थान से दूसरे स्थान और एक कंठ से दूसरे कंठ तक जाते-जाते इसके मूल रूप में कुछ परिवर्तन होते हुए भी लोकगाथाएं जीवित है। इनमें सच-झूठ, घृणा, प्रेम, द्वेष आदि को भी पूरी ईमानदारी के साथ प्रस्तुत किया जाता है। लोकगाथाओं में ग्रामीण जनता की भोली-भाली औपचारिकता से दूर, अनपढ़ एवं मासूम जनता के अनुभवों की सहज अभिव्यक्ति मिलती है। इसलिए इनमें स्थानीय मान्यताओं, विश्वासों और सामाजिक परम्पराओं का उल्लेख पूर्ण रूप से रहता है। ग्रामीण समाज की प्रतिदिन की बोलचाल की भाषा का प्रयोग होने के कारण अपने स्वाभाविक प्रवाह में लोकगाथा समाज को अधिक प्रभावित करती है। अतः लोकगाथा लोक साहित्य का गेयात्मक तथा पद्यात्मक रूप है जिसकी प्रधानता मानवीय मौखिक परम्परा है। लोकगाथा की कहानी महाकाव्य की तरह लम्बी होती है जो साहस, शौर्य, प्रेम, भक्ति, आदर्श आचरण के भावों और मानवीय मूल्यों को दर्शाती है।

लोकगाथाओं की परम्परा वैदिक युग से चली आ रही है। इसलिए इसके अर्थ को भी वैदिक युग से ही देखा जा सकता है। 'ऋग्वेद में 'गाने वाले' के अर्थ में गाथिन शब्द का प्रयोग किया गया है। वैदिक साहित्य में 'गाथिन' का प्रयोग उस व्यक्ति के लिए किया गया है जो किसी प्राचीन आख्यान या कला को कहने वाला हो।" अंग्रेजी में 'बैलेड' शब्द का प्रयोग लोकगाथा के लिए किया जाता है।

मानक हिन्दी शब्दकोश में लोकगाथा का अर्थ है- "परम्परा से चले आए हुए वे गीत जो लोक में प्रचलित हो।" आधुनिक हिन्दी प्रयोग में लोकगाथा परम्परागत गाथा शब्द से जिस प्रकार भिन्न है, वह है कथा की प्रधानता, क्योंकि वैदिक काल से लेकर अरण्यक, उपनिषद, ब्राह्मण, पुराण, प्राकृत रचनाओं तथा गाथा सप्तशती आदि में जहां-जहां गाथा शब्द प्रयुक्त हुआ वहां उसे गेयता और संक्षिप्त कथानक का ही द्योतक समझा गया है। आधुनिक गाथा की भांति प्रबन्धात्मक की प्रवृत्ति वहां नहीं है। अतः यह स्पष्ट हो जाता है कि आधुनिक गाथा में विशालता, गेयता तथा कलात्मकता इन तीनों तत्वों की त्रिवेणी आवश्यक है। गाथा में लोक विशेष लगने से ऐसी गाथा का भास होता है। जिनमें लोकमानवीय तत्व हो। अतः लोकगाथा शब्द लोक साहित्य की इस आख्यानपूर्ण गेय 
विधा का पूर्ण प्रतिनिधित्व करता है और इसी कारण हम इसके अन्य नामों से सहमत न होकर मात्र लोकगाथा नाम ही उचित मानते हैं।

\section{लाहौल-स्पिति की लोकगाथाओं में संगीत}

लाहौल-स्पिति में सबसे समृद्ध परम्परा लोकगाथाओं पर आधारित गीतों की रही है। लाहौल क्षेत्र में इन गीतों को 'घुरे' कहा जाता हैं स्थानीय भाषा अथवा चड्ग्रो भाषा जिसे हिन्दी में पट्टनी भाषा कहते हैं में यह घुरे गीत गाए जाते हैं। लाहौल क्षेत्र में यदि सभी घुरे गीतों को भाषा की दृष्टि से देखा जाए तो इसमें मिश्रित बोलियों का प्रयोग किया गया है। जिसमें लाहौल की सभी बोलियों के अतिरिक्त भोटी, कुल्लवी, चम्बयाली, गद्दी, पंगवाली आदि बोलियों का सम्मिश्रण है। इस तरह इनकी विषय वस्तु भी चम्बा, पांगी और कुल्लू के साथ किसी न किसी प्रकार का सम्बन्ध बताती है। गीत अतीत के संग्राहक श्री सतीश लोपा का कहना है कि- "इन गीतों के रचनाकार भेड़ की खाल से बनी ओढ़नी (थुल्पा) अथवा अन्य कोई वस्त्र सिर पर ओढ़ कर एकाग्रचित होकर गीत रचा करते थे और रचना पूरी हो जाने पर उचित अवसर पाकर इसे लोगों के बीच सुनाते थे।" इस तरह पीढ़ी दर पीढ़ी होते हुए इनकी यह अमुल्य निधि घुरे के रूप में हम तक पहुँची। लाहौल में जहां लोकगाथाओं को 'घुरे' अथवा 'यर गीत' के नाम से जाना जाता है, वहीं स्पिति में लोकगाथाओं को 'नामथर' तथा 'ज्ञालशू' कहा जाता है। इन लोकगाथाओं में अधिकतर सामाजिक, ऐतिहासिक व धार्मिक घटनाओं का वर्णन रहता है। जिनमें स्पिति में गाए जाने वाले 'नामथर' में केवल पौराणिक व धार्मिक गाथाएं ही होती है। जबकि 'ज्ञालशू' में सामाजिक ऐतिहासिक व धार्मिक तीनों प्रकार की गाथाओं का वर्णन का होता है। इन दोनों क्षेत्रों की लोकगाथाओं में केवल भाषा का अन्तर है। लाहौली लोकगाथाओं में जहां मिश्रित बोलियों का प्रयोग होता है वहीं स्पिति में लोकगाथाएं केवल भोटी भाषा में ही गाई जाती है। जिन्हें पारम्परिक लोकगायक मांगलिक और सांस्कृतिक अवसरों पर तो गाते ही हैं, अपितु सामान्य गोष्ठियों में भी इनका गायन होता है। इन गाथाओं में जीवन के प्रत्येक पहलुओं का वर्णन मिलता है। चाहे वह विवाह शादी की बात हो, मृत्यु, लोकजीवन, उत्सव, मेलों की बात हो तथा मिथकिय कथाओं की बात हो यह सभी विषयों से सम्बन्धित होते हैं इन गीतों को श्रुति परम्परा द्वारा एक विशेष समुदाय के लोकगायकों द्वारा आज भी बड़े चाव से गाया जाता है। सांगीतिक परिप्रेक्ष्य में लाहौल-स्पिति की लोकगाथाओं में सरलता, मधुरता, एवं रंजक तत्वों का व्यवहार प्रचुर मात्रा में मिलता है। इन लोकगाथाओं को गाने वाले एक विशिष्ठ लोक कलाकार होते हैं। इसमें पहले मुख्य गायक गीत की दो पंक्तियों को गाता है। उसके बाद मण्डली के दूसरे लोग उसी पंक्ति को दोहराते हैं इन गाथा गीतों के साथ नृत्य भी किया जाता है। इसमें नृत्य करते हुए ताल के स्थान पर केवल हाथों से थाप देकर गया जाता है। लाहौल क्षेत्र की 'भ्यार की गाथा' नामक पौराणिक लोकगाथा पर आधारित एक गीत की कुछ पंक्तियां इस प्रकार है- 
पोहला पुतूरा ए लाचा चारूणें गई जी ओ। पोहला पुतूरा ए बणां खांटे गई जी ओ। मेघे री धारे निजी मुरूता निकती जी ओ। निजी मुरूती सता मुरूता निकुती जी ओ। निजी मुरूती ए सता मुरूता खेला खेलूंदे जी ओ।

सता मुरूता स्नाना कीती जी ओ। रोज़े-रोज़े ए भेड़ा बकूरी दुधें जीओ।

एक मूरूता ए शांखे री जी ओ। पोहला पुतूरा ए यादा बिसारी जी ओ। चूरु रे सींगे पथुरा बाधाएं जी ओ। बोठी सेवीणी गाड़ी बवाड़ी दीती जी ओ। पोहला पूतूरा ए शदी करी आणीं जी ओ। पोहला पुतूरा ए अरूजाना धीती ओ।

\section{विशेषताएं}

लाहौल-स्पिति के लोकसाहित्य में लोकगाथा मुख्य और अमूल्य निधि है। लोक साहित्य की इस विधा को लाहौल में 'घुरे' और स्पिति में 'नामथर' व ज्ञालशुं आदि संज्ञा प्राप्त है। लोकगाथाओं की अपनी-अपनी तात्विक विशेषताएं है जिनमें इनकी सम्यक पहचान होती है। इन लोकगाथाओं की प्रमुख विशेषताएं निम्न प्रकार से हैं-

1. इसकी प्रमुख विशेषता यह है कि इसका रचनाकार अज्ञात होता है। लोकगाथा उसके रचनाकाल से ही कण्ठ परम्परा से चली आ रही है। रचनाकारों ने इन लोकगाथाओं की रचना कर जनसाधारण को सौंप दिया। इस प्रकार यह लोकसम्पत्ति बन गई। लोकगाथाओं में रचियता का वर्णन नहीं मिलता। अतः रचियता का आभाव ही लोकगाथा की महत्वपूर्ण विशेषता है।

2. लोकगाथा की दूसरी विशेषता में प्रमाणिक मूल भाव का आभाव है। यह नकारात्मक विशेषता ही इसकी उत्कृष्टता है। लाहौल में गाए जाने वाले 'घुरे' लोकगाथा केवल मौखिक रूप से प्रचलित है। जबकि स्पिति में गाए जाने वाली लोकगाथा नामथर लिखित रूप में भी प्राप्त होती है जो यहां के एक बौद्ध मठ में लिखित रूप में संरक्षित है।

3. गेयता लोकगाथा की प्राण शक्ति है। लोकगाथा में संगीत का सहचर्य इसकी गुणवत्ता को प्रस्तुत करने का विशेष तत्व माना जाता है। इसमें गीत व संगीत का सहचर्य चोली दामन जैसा होता है। लोकगाथा का लयात्मक गायन ही संगीत है। यह नीरस पदों में लयात्मकता से रोचकता पैदा करता है। गायक और श्रोता लोकगाथा में अर्थ, गम्भीरता, पद, लालित्य ना होने पर भी मात्र लय में तल्लीन होकर मंत्रमुग्ध हो जाते हैं। 
4. इसमें गेयता के साथ-कथानक की प्रधानता रहती है। एक गीत थोड़े बहुत परिवर्तन के साथ युगों तक चलता है। बहुधा नया गायक सामाजिक, सांस्कृतिक परम्पराओं के अनुसार नवीन विचार या बोल इसमें मिला देता है। फलतः गीत में कुछ परिवर्तन भी होता है।

5. लाहौल स्पिति की लोकगाथाओं की महत्वपूर्ण विशेषता यह है कि इसमें स्थानीयता का पुट विद्यमान रहता है। जिससे जनमानस के समस्त क्रिया-कलापों, धार्मिक आस्थाओं तथा पारम्परिक रीति-रिवाजों का वर्णन विशेष रूप से रहता है।

6. इसकी एक अन्य विशेषता यह भी है कि इन लोकगाथाओं का प्रत्येक पद अन्य लोकगाथा की भांति चार चरणो में न होकर प्रत्येक पद दो ही चरण के है। यह दो पद गेयता की सुविधा में महत्वपूर्ण भूमिका निभाते है। जिससे लय और ताल में सरलता रहती है।

7. लाहौली लोकगाथा 'घुरे' की एक विशेषता यह भी है कि इन गाथा गीतों के साथ वाद्य यन्त्रों का प्रयोग न के बराबर किया जाता है। कुछ गीत तो ऐसे भी होते है जिनके साथ वाद्यों का प्रयोग बिल्कुल नहीं होता केवल हाथों से थाप देकर इसका गायन होता है।

\section{उपसंहार}

लोकगाथा लोकसंस्कृति का ऐसा आईना है जिसमें जन समाज और उसके परिवेश का सम्पूर्ण चित्र स्पष्टतः दृष्टिगोचर होता है। इन गीतों में ऐतिहासिक, धार्मिक, सांस्कृति व पारम्परिक दृष्टिकोण निर्वावाद है। लाहौल स्पिति में लोकगाथाओं का स्थान विशिष्ठ एवं महत्वपूर्ण है, जिसे यहां के लोग अपनी सांस्कृतिक धरोहर मानकर आज भी मौखिक रूप से संजोए हुए है।

लाहोली लोक संगीत के अन्तर्गत लोकगाथाओं का यहां के जनजीवन से घनिष्ठ सम्बन्ध रहा है। घुरे गीत अपने आप में एक इतिहास समेटे हुए है जिसमें प्राय: वीर पुरुष, सती-नारी, बलिदान, श्रृंगारिक तथा प्रणय से सम्बन्धित कथानक विशेषकर समाहित रहते है। लोकगाथाओं की यह परम्परा मौखिक रूप से पीढ़ी दर पीढ़ी अपने विकास पथ पर अग्रसर होकर आज भी पारम्परिक रूप से विद्यमान है। जहां तक लोकगाथाओं की उत्पत्ति का विषय है इसमें विद्वानों के भिन्न-भिन्न मत है। इसलिए कल्पना या अनुमान के आधार पर किसी एक मत को पूर्ण रूप से स्वीकारा भी नहीं जा सकता है। मूल रूप से लोकगाथा किसी व्यक्ति विशेष के प्रयास से ही बनती है। जिसमें वह व्यक्ति किसी घटना और सुन्दरता का वर्णन इन गीतों द्वारा करता है। इस तरह उनकी रचनाएं गाथा गीत के रूप में एक सामाजिक अमूल्य निधि बन जाती है। इस प्रकार लोकगाथाओं में अनेक विशेषताएं तो मिलती है मगर किस काल में किस गीत की रचना किस व्यक्ति द्वारा की गई यह पता लगाना बड़ा कठिन है। लोकगाथाओं का आख्यान बड़ा लम्बा होता है। लोकगाथाओं में टेक पदों की पुनरावृत्ति इसकी प्रमुख विशेषता है। जिसे बार-बार दोहराने पर उस में आन्नद रूपी रस और ज्यादा मीठा होता जाता है। 
लोकगाथाओं की परम्परा भी अति प्राचीन है जिसका कोई ठीक विवरण नहीं है। मौखिक रूप से यह परम्परा आज भी कहीं न कहीं, किसी न किसी घाटी के वृद्धजनों के पास विखण्डित रूप में सुरक्षित है। इन लोकगाथाओं का विषय और स्वरूपगत आकार भले ही लघुकाय है; लेकिन कथात्मक गेयात्मकता और अन्य गुणों से अपने आप को पूर्ण प्रमाणित करती है। इस समूचे क्षेत्र में मुख्यतः सर्दियों के तीज त्यौहारों, विवाहोत्सवों में गाथा गीतों का गायन जनसाधारण के मनोरंजन के लिए किया जाता है। जिनमें सामाजिक, धार्मिक व पौराणिक तथा ऐतिहासिक लोकगाथाएं प्रमुख है। इन गाथा गीतों के शब्दों में स्थानीय बोलियों के अलावा चम्बयाली, कुल्वी एवं भोटी इत्यादि बोलियों का सम्मिश्रण होता है।

लाहौली लोकगाथाओं की धुनों में जीवन्तता का आभास मिलता है। गाथा गीतों में ऊंचे स्वरों (मध्य सप्तक के मध्यम) को आधार मानकर गाया जाता है जिसमें आवाज प्रभावशाली तथा स्पष्ट सुनाई देती है। यहां की अधिकतर लोकगाथाएं ताल रहित तथा अनिबद्ध प्रकार के है। इनमें केवल हाथ से थाप दी जाती है जिससे अप्रत्यक्ष रूप से लय अथवा ताल का आभास होता है जो दादरा, चाचर तथा दीपचन्दी ताल के समान प्रतीत होते है। इन गीतों में पद के आरम्भ और अन्त में 'ए' और 'ओ' का स्वर उच्चारण हमेशा सुनने को मिलता है। प्रत्येक गाथा गीतों में किसी न किसी राग जैसे पहाड़ी, दुर्गा, भूपाली तथा भीमप्लासी आदि रागों की छाया देखने को मिलती है।

\section{सन्दर्भ}

शर्मा श्री राम (1997), लोक साहित्य और मूल्यांकन, निमर्ल पब्लिकेशन, दिल्ली।

वशिष्ट सुदर्शन (2011), लाहुल-स्पिति, सचिव, हिमाचल कला संस्कृति भाषा अकादमी शिमला, हिमाचल प्रदेश।

ठाकुर डॉ. सूरत (2015), हिमाचल प्रदेश का जनजातीय लोकसंगीत, शिवांक दरियागंज नई दिल्ली।

वर्मा रामचन्द (1965), मानक हिन्दी कोश, चौथा खण्ड, प्रयाग : हिन्दी साहित्य सम्मेलन ऋग्वेद, 8:32:1 गीता प्रेस गोरखपुर।

शोंडा, आचार्य प्रेम सिंह (2010), चन्द्रताल पत्रिका, हिमाचल कला संस्कृति एवं भाषा अकादमी शिमला।

इन्साइक्लोपीडिया ब्रिटानिका (लंदन; विलियम बेटन पब्लिशर, 1943-1973। मैक्सफोर्ड डिक्शनरी, इंगलिश-इंगलिश-हिन्दी, नीरज पब्लिकेशन, दिल्ली। 